\title{
Mathematical model of energy storage for the calculation of electromechanical processes in power systems
}

\author{
V.M. Zyryanov ${ }^{1}$, N.G. Kiryanova ${ }^{1, *}$, G.B. Nesterenko ${ }^{1,2}$, A.M. Potapenko², G.A. Prankevich ${ }^{1}$ \\ ${ }^{1}$ Novosibirsk State Technical University, Department of Automa ted Electrical Power Systems, 20, Prospekt K. Marksa, \\ Novosibirsk, 630073, Russia \\ 2Energy Storage Systems LLC, 14/1, Serebrennikovskaya str., Novosibirsk, 630007, Russia
}

\begin{abstract}
The paper proposes and describes a mathematical model of an energy storage system based on a battery energy storage system as part of an electric power system for calculating transient electromechanical processes. The reliability of the model is confirmed by full-scale experiments in an autonomous power system with an abruptly variable load. The model is intended for use in modern software systems to analyze the stability of power systems.
\end{abstract}

Keywords: Energy storage system, mathematical model, battery energy storage system, autonomous power system, abruptly variable load.

Received on 31 May 2018, accepted on 03 August 2018, published on 02 October 2018

Copyright (c) 2018 V.M. Zyryanov et al., licensed to EAI. This is an open access article distributed under the terms of the Creative Commons Attribution licence (http://creativecommons.org/licenses/by/3.0/), which permits unlimited use, distribution and reproduction in any medium so long as the original work is properly cited.

doi: 10.4108/eai.13-7-2018.155645

*Corresponding author. Email:kiryanova-ng@ya.ru

\section{Introduction}

The progress in the development of energy storage technologies makes it possible to predict in the near future significant changes in the organization of the functioning of energy systems. In connection with the advent of an energy storage unit in the power system, it will be necessary to revise the circuit and regime solutions, the composition of the equipment, the planning, optimization and maintenance of regimes, as well as the emergency control system.

Fast-speed energy storage devices already have acceptable technical and economic performance. This is a battery energy storage systems (BESS), supercapacitors, electromechanic energy storage and superconducting magnetic energy storage (SMES). It is more correct in this case to use the term energy storage system (ESS) because the energy storage device for connection to the power system requires a system communication device (SCD). Currently, the most actively developing ESS with BESS.

ESS is a multifunctional device and in addition to active power control, it is capable of simultaneously performing the functions of a reactive power control device, an active filter of higher harmonics, as well as a three-phase voltage asymmetry compensation device.

Fast-speed ESS already comprehensively and much more effective allow solution of a number of complex problems much more efficiently than traditional methods [1-8].

The greatest technical and economic effect of ESS at the present level of energy storage technologies can be obtained in isolated power systems with distributed generation, in Smart and Micro Grids, in autonomous power systems of oil and gas sector of the economy. In the latter case, power supply systems is dominated by consumers with stochastic abruptly variable load, the power of which is commensurate with the capacity of generating units (diesel, gas turbine and gas piston power units). The requirements for ESS for such power systems in terms of power and energy capacity are minimum, quite realizable at the present time. This circumstance makes it possible to accumulate field experience, to work out algorithms and control laws, and to prepare mathematical support for the study of power systems with ESS. The development of the technology and the inevitable reduction of the working cost also will make a 
demand for ESS in the large power systems. There are many actual tasks for ESS in large power systems.

Appropriate mathematical models are needed for the calculation of regimes and transients in power systems. Such models should be integrated into the modern software systems. The article is devoted to the development of a mathematical model for the calculation of transient electromechanical processes in the power system, which includes ESS based on BESS. Modeling is carried out on the example of the simplest power system: diesel-generator unit - ESS - abruptly variable active-inductive load.

\section{The main requirements to ESS model}

To study the transient processes in power systems with ESS, depending on the task posed, mathematical models of various purposes of different degree of modeling accuracy are necessary. In this paper, we propose a model designed for the calculation of electromechanical transients. Model main purposes are to evaluate the correctness of the choice of parameters of ESS, to test various algorithms for controlling ESS, to show workable and efficiency of these algorithms. A model of this kind should allow us to calculate transient electromechanical processes taking into account the controlled exchange of active and reactive power of ESS and the power system with the main limitation imposed by the characteristics of BESS and SCD [9]. Detailed and accurate simulation of the processes in the reversible transistor converter and in the battery for this model is not required.

\section{Description of the mathematical model}

A mathematical model of an autonomous power system with using of ESS was developed in the Matlab / Simulink software package. The model includes three main elements: a diesel generator unit (DGU), a load and an energy storage system (Fig.1).

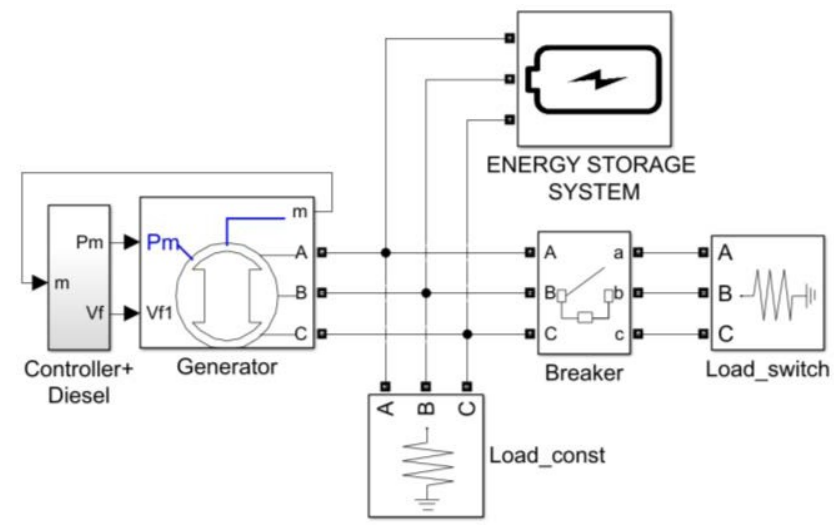

Figure 1. Structural diagram of a mathematical model of an autonomous power system

The DGU model consists of a synchronous generator model equipped with an automatic voltage regulator (AVR) and a diesel engine model with an automatic speed regulator (ASR). AVR is a typical excitation regulator according to the IEEE type 1 model [10]. The model proposed in [11] was used as a model of a diesel engine with an automatic speed regulator. The block diagram of the regulators is shown on Fig. 2.

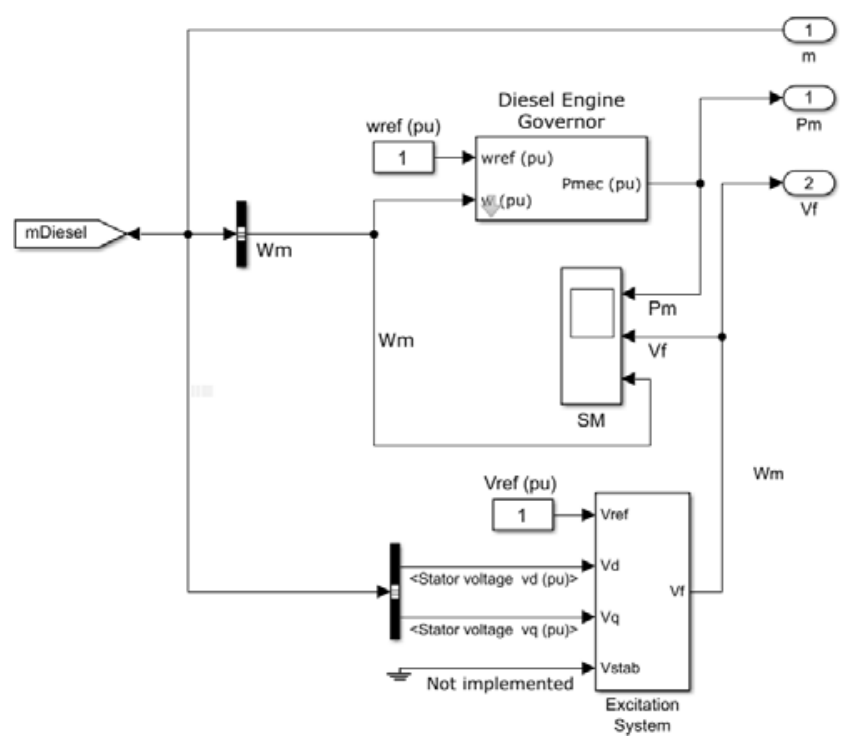

Figure 2. Model of AVR and ASR of diesel generator

To reduce the calculation time in the study of long electromechanical transients, the ESS model was developed on the basis of a three-phase controlled power source without using detailed models of a transistor converter and batteries (the energy storage subsystem is specified by its external characteristic). This solution allows us to increase the calculation step by several orders of magnitude, which in turn reduces the requirements for computing power, and also allows us to calculate electromechanical transients lasting several tens of seconds. The general structural diagram of ESS is shown on Fig.3. A controlled power source is used as a mathematical model of the main power element of ESS. In addition, the ESS model includes three blocks: a block for setting the basic parameters of ESS; a block that simulates the functioning of ESS subsystems in time; block of the control of the power of ESS.

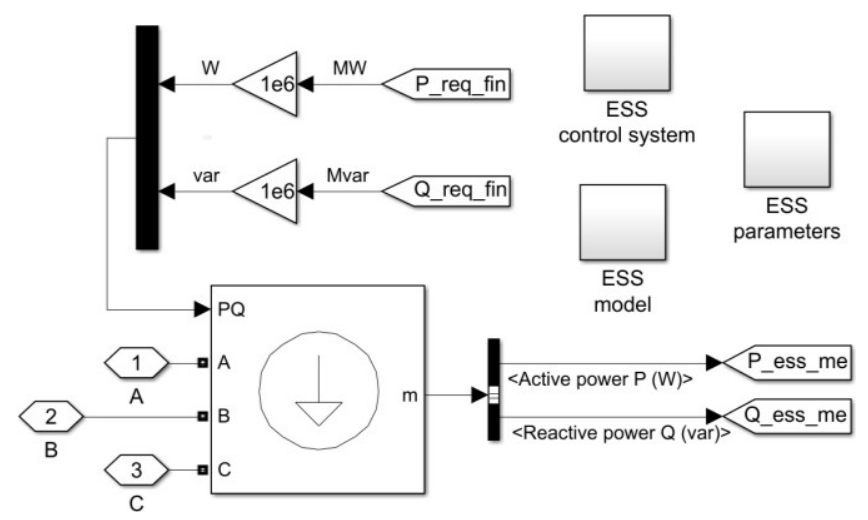

Figure 3. The general structure of the ESS model 
In the parameter block, the parameters of ESS are set: the nominal energy capacity, the nominal power, the initial charge level, the maximum and minimum charge limits, and the possibility of limiting the rate of change in power (discharge / charge current).

The block that simulates the functioning of ESS subsystems in time is a set of elements and functions that allow the controlled power source to produce/ consume energy according to a given algorithm, taking into account the specific features of ESS. The block performs the following functions: calculating the current value of the charge level, limiting the maximum / minimum charge level, limiting the required power (the value generated by the control system) to the value of the available power of ESS, limiting the maximum value of the charge and discharge current, limiting the rate of change of the charge and discharge current, also a delay in time, reflecting the finite speed of the control system of the transistor converter.

In the block of the control of the power of ESS, algorithms are implemented that realize the specified modes of operation.

\section{Verification of the mathematical model}

The evaluation of the reliability of ESS model was carried out by comparing the results of the calculation with the results of the field experiment. The experiments were carried out with a ESS power of $100 \mathrm{kVA}$ and energy capacity of $153 \mathrm{kWh}$ with Li-iron-phosphate batteries LTLYP300AH as part of an autonomous power system with a diesel generator unit EDD-100 with a power of $100 \mathrm{~kW}$ (125 kVA) operating at an abruptly variable load (Fig.4). The experiments were performed at the production site of LLC "Systems of Permanent Current" in Novosibirsk by the specialists of LLC ESS and NSTU.

Comparison of calculated and experimental results is carried out on the example of two control algorithms ESS: limiting the load power at the given upper and lower limits and limiting the magnitude of the current derivative of the DGU $(d I / d t)$ with sudden changes in the load power.

Due to the lack of accurate factory data, the parame ters of the diesel generator and its regulators in calculations were adopted by standard ones.

\section{The control experiment}

The control experiment without ESS (Fig. 4, 5) was carried out with a short-term nature of the change in the active load: cycle duration $10 \mathrm{~s}$, duty cycle 0.5 .

\section{Load power limitation}

The experiment with the ESS, working according to the algorithm for limiting the maximum and minimum load power at the DGU (Fig. 6, 7) was carried out in the same sequence as the control one. Settings: minimum power 45 $\mathrm{kVA}$, maximum - $65 \mathrm{kVA}$ ). When the output of the load exceeds the limits of the specified values, the difference between the setpoint and this power consumes or gives out ESS.

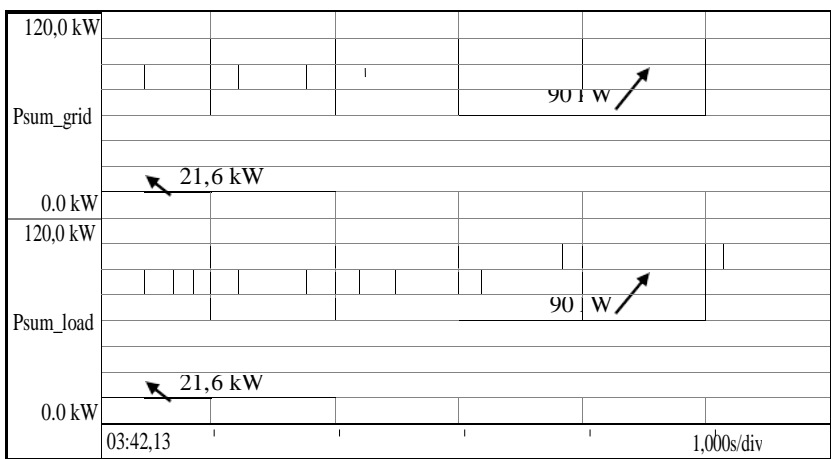

Figure 4. Experiment: transient process without ESS (from top to bottom - the power of the DGU, the load power)
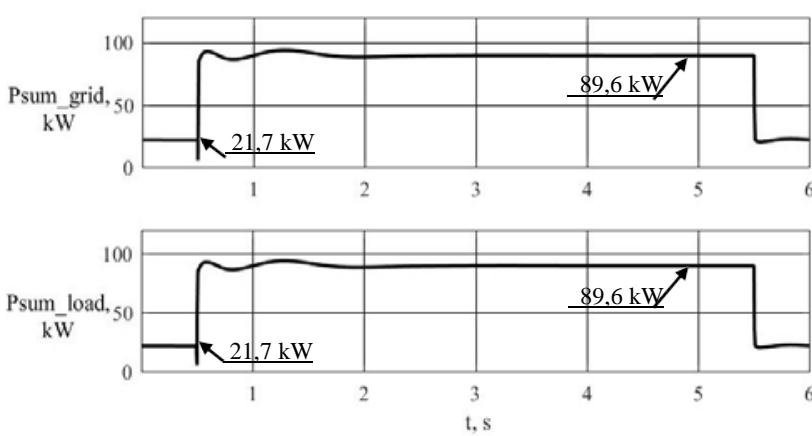

Figure 5. Calculation: transient process without ESS (from top to bottom - the power of the DGU, the load power)

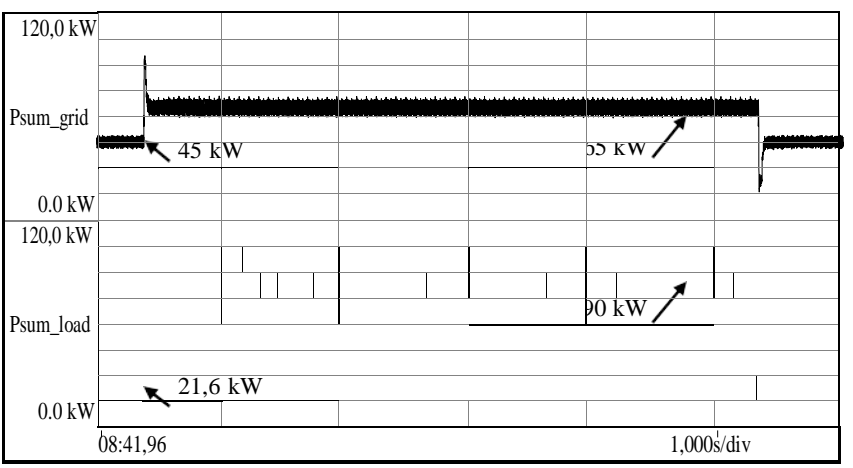

Figure 6. Experiment: transient process with ESS in the Power Limit Mode (from top to bottom - the power of the DGU, the load power)
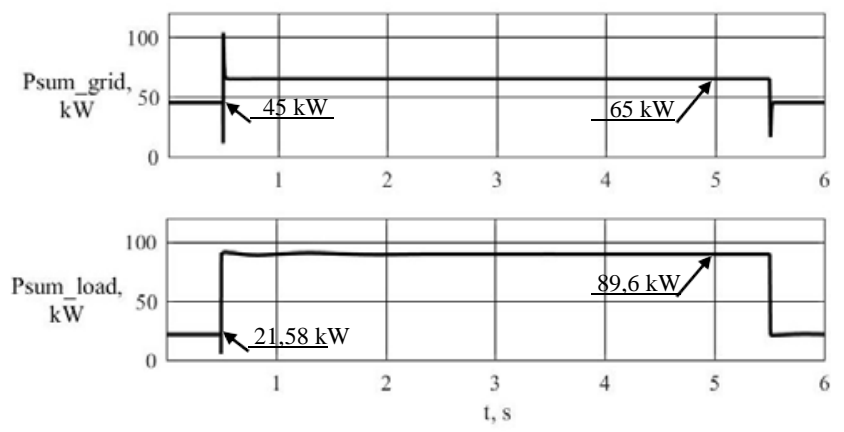

Figure 7. Calculation: transient process with ESS in the Power Limit Mode (from top to bottom - the power of the DGU, the load power) 
Limiting the rate of change in load power

The experiment with the ESS working on the algorithm for limiting the rate of change in load power at the DGU was carried out in the same way as the previous one, but the control algorithm of the ESS limited the magnitude of the current derivative $d I / d t$ of the DGU (Fig. 8, 9).

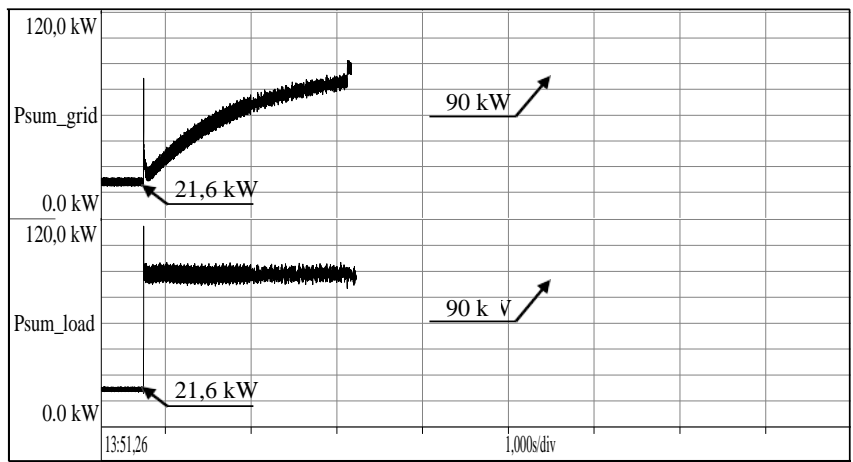

Figure 8. Experiment: transient process with ESS in the $d l / d t$ Limitation Mode (from top to bottom - the power of the DGU, the load power)
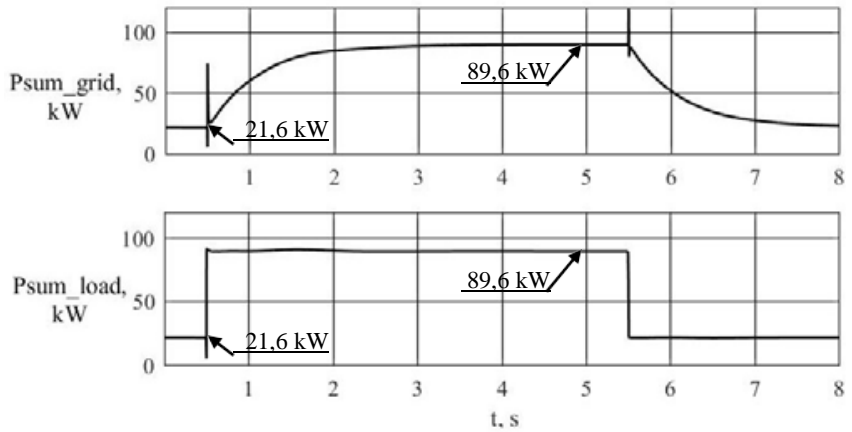

Figure 9. Calculation: transient process with ESS in the $d I / d t$ Limitation Mode (from top to bottom - the power of the DGU, the load power)

\section{Examples of calculation of transition processes on results of monitoring of energy objects}

\section{Pontoon crane}

Fig. 10 shows the calculation for an autonomous power system of a pontoon crane. Load is characterized by an abruptly variable diagram (the lower oscillogram in Fig. 10), which is fully compensated by DGU with installed power $300 \mathrm{~kW}$. The average load per cycle is $67.7 \mathrm{~kW}$, and the utilization factor of the installed power is $22 \%$ [5]. In addition, at the load diagram there are intervals of time during which the energy is recuperated. In this case, the generator goes into an motor mode and accelerates the diesel engine. This mode of operation is typical for load-lifting mechanisms of cyclic action. The variable part of load diagram compensates by ESS. In this exmpale the ESS was tuned to limit the power of DGU in the range from 56.7 to $76.7 \mathrm{~kW}$. The loading diagram with apllying of ESS with DGU is shown on the upper oscillogram of Fig. 10. It becomes possible to reduce the installed power of the diesel generator set by 3 times. The remaining uncompensated relatively high-frequency power oscillations of the DGU do not have a significant effect on the generator set [8].

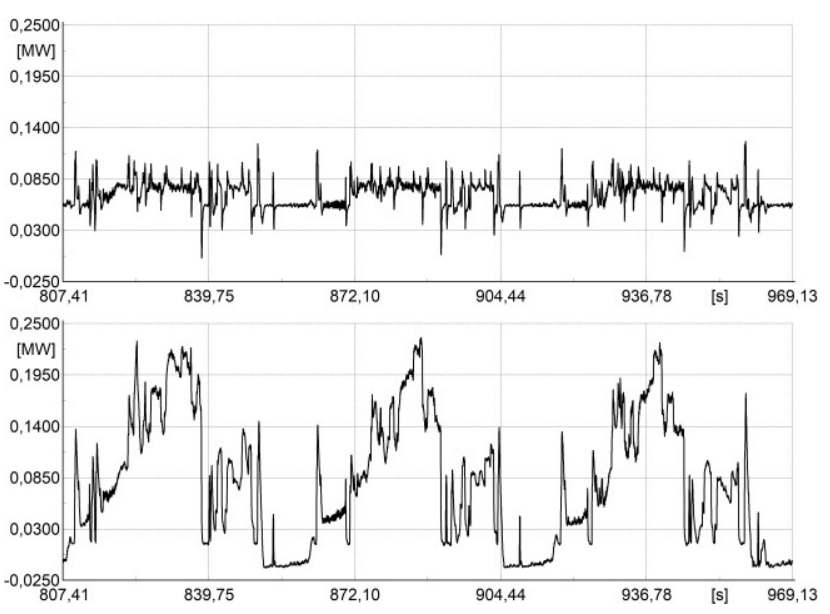

Figure 10. Calculation: transient process of the pontoon crane operation with ESS in the regime of limiting the deviations of the load from the mean value (from top to bottom - the power of the generator, the load power)

\section{Drilling installation}

Fig. 11 shows the simulation results for an example of a drilling installation in normal technological process. The autonomous power system of the drilling installation consists of three DGU with a nominal capacity of $1 \mathrm{MW}$. At the considered time interval (740 s - $960 \mathrm{~s})$ there is a load dumping (from 1.9 MW to 0.7 MW). Such disturbance can lead to emergency outage of gas piston units (GPU). For this case, an algorithm is implemented to limit the rate of change in the load power $(d P / d t \leq 100 \mathrm{~kW} / \mathrm{s})$. The front of the change in the load power was stretched from $0.04 \mathrm{~s}$ to $12 \mathrm{~s}$ with the help of the ESS. That provides an acceptable mode of GPU operation.

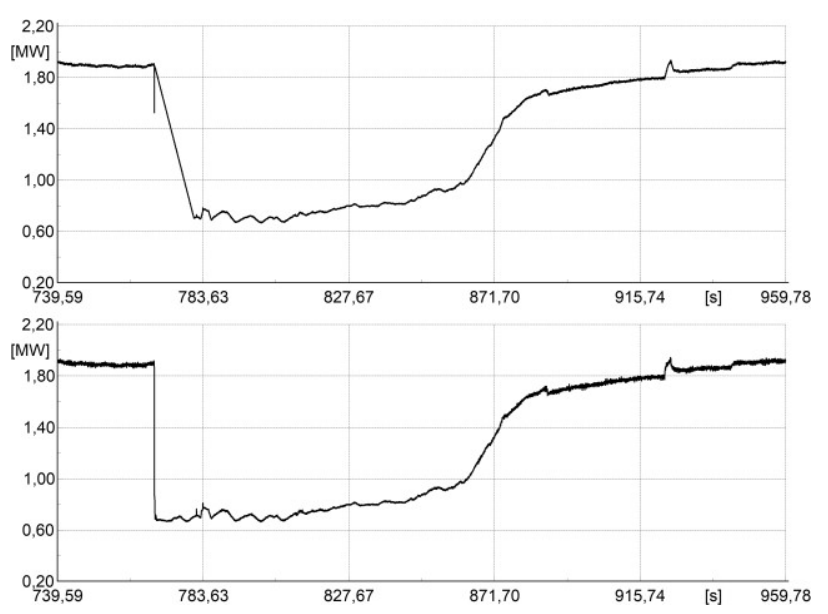

Figure 11. Calculation: transient process of the drilling installation operation with ESS in the regime of limiting the rate of change in power (from top to bottom - the power of the generator, the load power) 


\section{Conclusion}

Comparison of calculated and experimental oscillograms shows not only qualitative, but also quite satisfactory quantitative coincidence of the results, which confirms the reliability of the proposed model of ESS and the possibility of its use in modern software systems for the calculation of transient electromechanical processes in power systems that use energy storage systems based on BESS.

\section{References}

[1] Berdni KOV, R.N., Fortov, V.E., ShaKarJan, Ju.G., DENSHHIKOV, K.K. (2013) Hybrid energy storage for UNPG based on batteries and supercapacitors. Energy of Unified Grid 1: 40-51. (in Russian)

[2] The Ministry of Education and Science of Russia (2018) “The first Russian energy storage system of high power was developed at the NSTU”. [Online]. Available: https://минобрнауки.pф/новости/12328. (in Russian)

[3] Robyns, B., François, B., Delille, G., Saudemont, C. (2015) Energy Storage in Electric Power Grids, (UK: ISTE and John Wiley \& Sons).

[4] Kononenko, V.Ju., Veshrunov, O.V., Bilashenko, V.P., SMOLENCEV, D.O. (2014) Effects of the use of energy storage in isolated power systems in Russia. Arctic: Ecology and Economy, 2(14): 61-66. (in Russian)

[5] Alemasov, V.A., Baranov, D.I., Bimukhanov, M.D., Zyryanov, V.M., MosienKo, A.B. (2007) Efficiency of the use of energy storage devices in autonomous power systems with an abruptly variable load. Scientific problems of transport in Siberia and the Far East 2: 113-120. (in Russian)

[6] Efremov, D.G., GlousKin, I.Z. (2017) Increasing of electrical generator transient stability by controlling a group of energy storage devices of various types. Vestnik IGEU 6: 5-14. (in Russian) DOI: 10.17588/2072-2672.2017.6.005014.

[7] Arestova, A.Y., Gorte, O.I., KhMELIK, M.S., Kiryanova, N.G., Grobovoy, A.A. (2016) Energy storage unit as a tool for emergency control on an example of the Russky Island power network. Automation and IT in the energy sector, 5(82): 15-22. (In Russian)

[8] Kiryanova, N.G., Baluev, D.Y., Prankevich, G.A., ZYRYANOV, V.M. (2017) Energy storage device application for load oscillations damping in isolated power systems. In Proceedings of Actual issues of mechanical engineering (AIME 2017), Tomsk, Russia, 27-29 July 2017 (Advances in Engineering Research 133: 325-330). DOI: doi:10.2991/aime17.2017.53.

[9] Voroshi lov, A., Petrov, A., Chudinov, E. (2017) Lithiumiron-phosphate battery. Modeling the charging regime. Electrical Engineering News 2(104)-3(105): 44-49. (in Russian)

[10] IEEE Std 421.5-2016 (2016), Recommended Practice for Excitation System Models for Power System Stability Studies (Redline Revision of IEEE Std 421.5-2005) (USA: IEEE Power and Energy Society).

[11] Sybi Lle, G., Zavaiou, T. Emergency Diesel-Generator and Asynchronous Motor [Online]. Available: https://www.mathworks.com/help/physmod/sps/examples/em ergency-diesel-generator-and-asynchronous-motor.html. 